\title{
ranserix \\ Bioactivity—Symphony or Cacophony? A Personal View of a Tangled Field
}

\author{
Brian W Darvell
}

check for updates

Citation: Darvell, B.W Bioactivity-Symphony or Cacophony? A Personal View of a Tangled Field. Prosthesis 2021, 3 , 75-84. https://doi.org/10.3390/ prosthesis 3010008

Received: 26 January 2021

Accepted: 25 February 2021

Published: 2 March 2021

Publisher's Note: MDPI stays neutral with regard to jurisdictional claims in published maps and institutional affiliations.

Copyright: (C) 2021 by the author. Licensee MDPI, Basel, Switzerland. This article is an open access article distributed under the terms and conditions of the Creative Commons Attribution (CC BY) license (https:/ / creativecommons.org/licenses/by/ $4.0 /)$.
Dental Materials Science, University of Birmingham, Birmingham B15 2TT, UK; b.w.darvell@bham.ac.uk

\begin{abstract}
In the pursuit of better treatments, the concept of a chemically-active material, responding to local conditions by causing reactions, or reacting to produce substances that are deemed beneficial, seems laudable. Ultimately, the goal appears to be to recruit natural biological processes such that a natural 'repair' is effected. This goal seems to be the reason for prefixing "bio-" to many terms with a view to advertising the desire, yet without presenting evidence that it has occurred, or indeed that it is capable of occurring, relying instead on non-biological processes to justify the claims. The dogma is such that all work where local 'responsive' chemistry is involved must receive the label "bioactive" to legitimize and promote. Nevertheless, the primary evidence adduced is flawed, and the claim must fail. A rethink to restore scientific sense and confidence in the endeavour is essential if real progress is to be made.
\end{abstract}

Keywords: bioactivity; bone; dentistry

\section{Overture}

Dentistry has evolved through a progression of emphasis, largely dependent on the state of knowledge of anatomy and physiology, but ultimately controlled by the technology available. The history is nuanced - a braided tale: regional, cultural, personal, politicalbut can be distilled. Thus, simple relief of pain (cloves, extraction) was followed by an improvement of or return to function with fillings: a variety of substances called into service through a combination of convenience, tradition and enthusiasm, albeit with some well-intentioned but unaware practitioners. Missing teeth were dealt with in a variety of ways, as has been well-documented elsewhere, e.g., [1], and again dependent on the materials' technology. Despite the increasing emphasis on prevention (but with a long way to go), the development of fillings and related treatments has in the recent few decades made important progress.

At this point I am breaking off for a moment to explain why I did not use the word 'restoration' instead of what is increasingly seen as an old-fashioned and outdated term, 'filling', and give a cue for what follows. It is a 'weasel' word [2]: the implications go beyond what is a reasonable interpretation, and in fact set the scene for the subject of this special issue. The primary purpose of a filling is to occlude the hole in the tooth, perhaps to reduce the risk of further damage, limit or avoid pain, and in the case of occlusal surfaces re-establish function. It is, in a loose sense, a repair, but clearly only foreign materials are involved - all such are in fact prosthetic devices. The same can be said of crowns and veneers. But in no sense has the tooth as such been 'restored' to its former state. Missing tissue has been replaced, that is all. Weasel words occur in many contexts in dentistry.

To resume: That progress has encompassed the now almost universal focus on "toothlike" materials for tissue replacement, where the goal is the mimicry of appearance such that the treatment is invisible to casual observation, in so-called 'aesthetic' dentistry (a meaningless usage, another weasel word) (pp. 618-619, [3]). Undoubtedly, such work has improved the quality of life for many people, although for longevity, sealing, retention and bonding it has yet to achieve in practice what is claimed. In that light, then, methods and materials that enable or promote some kind of self-sealing or self-repairing process would 
appear to be desirable. This would seem to make such materials "smart", [4] were they to exist, where we might note in anticipation the following remark:

“... smart materials are also known as responsive materials. These are usually translated as "active" materials although it would be more accurate to say "reactive" materials."

That is to say, they are passive until triggered externally. This is a point that seems to have escaped general attention in the present context: they do not do anything on their own.

Dentistry does, of course, extend further than the functional repair or replacement of teeth, most obviously through the use of implants to carry larger prostheses. Various other interventions in bone are necessary, whether arising from disease, surgery, or developmental problems, in order to provide function and anatomy, and indeed permit the use of dental implants. This kind of activity extends naturally to the general maxillofacial context, most dramatically in facial reconstruction. In this context, we encounter the distinction between replacement materials that are simply inert (which broadly speaking have been found to be unserviceable) and those that form some kind of union with tissue, beyond, that is, fibrous encapsulation. It is here that we run into another weasel word-bioactivity.

\section{What Is Bioactivity?}

If we start from first principles, it would seem proper to begin by defining a bioactive substance as one that is naturally-occurring, part of a normal biological process, and serving to trigger or modulate a biochemical pathway (whether or not the outcome is desirable is another matter). Here we have to be sure that we are talking about substances that are or may be produced by the body, whether in health or disease, without external supply. However, it is equally obvious that pharmaceutical products are deliberately bioactive [5]. They are intended, for example, to disrupt the functioning of some invading species, rectify a disease state whereby some substance is deficient, absent or in excess, or modulate a process that is somehow out of kilter and thereby causing a disease of greater or lesser severity. We may cite insulin for diabetes or vitamin D for lack of sunshine exposure, say, for natural processes, while antibiotics for infections and salicylates for headache are examples of a 'foreign' substance intervention, even if they are naturally occurring in other species. The emphasis remains on the targeted natural processes. Of course, pharmaceuticals go well beyond that in that most now are entirely synthetic, and thus alien (even if derivative), yet it remains that their mode of action is of the same kind, whether they are mimics or disrupters, say. Indeed, active substances in 'herbal' remedies are of the same class: alien but active in that they affect a normal process. Similarly, 'active' substances in foodstuffs beyond those needed for normal dietary reasons (most obviously nutrition) would have to be so labelled. Now, the question is whether the vehicle for the active ingredient can be labelled in the same way. Logically not, even if common speech blurs such distinctions, in the same way that the messenger is not the message, and the excipients of a tablet are not the drug. We are supposed to be scientific: objective, evidence-based, accurate and precise, or at least trying to be. This puts strong constraints on what we might legitimately call a 'bioactive material'. Thus, only a substance that of itself has the desired property of biochemical involvement could possibly warrant the label with full legitimacy. Nevertheless, we need to relax the point somewhat, both semantically and operationally, in order to speak and work at all, providing we keep the distinctions clear in our mind and not fall foul of fallacious reasoning. Thus, we may extend the label, with care, to a composite structure where one or more components have that character.

There are other ways of affecting normal physiological processes, but in just two classes: what we may term simple chemical, and challenge defence. A simple chemical response is obtained, for example, when a chemical species is introduced that perturbs a local chemical equilibrium, or the gradient of a dynamic process of homeostasis, such as by changing a key concentration or affecting the local $\mathrm{pH}$. A relevant example is a material that is a source of calcium ions. In the ordinary physiology, body fluids are essentially just saturated with respect to biological apatite (BAp). Were this not so bones would simply 
dissolve (compare the dissolving of mollusc shells and coral reefs in an acidifying ocean), or spontaneous calcifications would occur if nucleated, such as by trauma. Neither happens ordinarily. Yet supply an excess of calcium, as for example from calcium hydroxidecontaining cements (as in liners and hydraulic silicates), and biological-like apatite forms. This is inevitable, basic chemistry. There is no biological process involved, even if the context, the immediate environment, is biological. Thus, any material which through degradation or simple dissolution provides such ions must produce a calcium phosphate locally. We are obliged to ask, therefore, whether the material that provides those ions can legitimately be labelled "bioactive". My answer is no. There is currently no dental material or product that passes this test, nor any obvious prospect of one. Indeed, the concept that "bioactivity of a material usually denotes that the material is capable of forming hydroxyl apatite mineral on its surface: in vitro and in vivo" is accepted without demur [5]. However, they go on to say they that the term should be restricted to materials that "release substantial quantities of ions" - ending by asking for debate and consensus on what constitutes "substantial", which shifts the definition to a matter of degree, and which is a little odd for science.

It is a curious thing but the literature is replete with tests of 'bioactivity' that involve immersion of the latest candidate wonder material in a metastable supersaturated solution of calcium and phosphate, often under the guise label of a 'simulated body fluid' (SBF) which, again, is not what it purports to be [6]. The test criterion is simply the appearance in due course, if not rather promptly, of an apatitic precipitate on that material [7]. Unfortunately, almost everything produces that effect, with a variety of crystal habits, due to the ease with which apatitic material nucleates under those circumstances. The force of this observation lies in the fact that highly supersaturated calcium phosphate solutions can be prepared that can stand for days without doing anything at all. The thermodynamic demand is clear, yet homogeneous nucleation is so unfavourable that nothing may happen, the kinetic limitation. However, just shaking the flask results in the prompt and nigh on complete precipitation of the excess: any seed is enough. This is why they are labelled metastable - they await 'activation'. It is worth stressing: there is no discernible chemical difference between such a system and the above-mentioned 'bioactivity' test. There is simply no biology involved [6].

A major difficulty lies in the referencing chain. Thus, for example, Vallittu et al [5]. said: "materials that are able to have a biological effect or be biologically active, and form a bond between the tissues and the material, are called bioactive materials" and cite [8]. However, the word 'bioactive' does not appear in that paper. Even so, the definition rather narrowly hinges on the formation of a bond, a definition that has been enshrined in ISO 23317 [9]:

\section{“3.3. Bioactivity}

property that elicits a specific biological response at the interface of the material, which results in the formation of a bond between tissue and material"

These logical leaps are unhelpful, but they do illustrate a general problem with the audit trail, so to speak, for concepts in the field.

Thus, a recent review [10] has the following statement:

"For the purposes of this review, a [bioactive glass] is defined as a glass capable of forming an apatite layer when immersed in physiological solutions."

This is a plain admission of the absence of biology, a purely passive, simple chemical outcome of the reactivity of the glass and the composition of the medium. Thus, there is - by definition! - no biology involved, merely SBF, or occasionally other media such as distilled water. In fact, that such reactions occur in water alone underlines the point so strongly that it is difficult to see how the label can then be applied without embarrassment. Reactive is the best that can be said.

The second class of behaviour, challenge defence, is the physiological response to an insult, elicited by anything that represents a foreign body, toxicity, osmotic imbalance, 
boundary layer disturbance (via zeta potentials or surface chemistry), $\mathrm{pH}$ change, or merely unusual ions - that is, a chemical challenge to the viability of a tissue, to homeostasis. The material is plainly not inert (i.e., not 'invisible' to the system), and it follows that the body's natural reaction is to mount a defensive response. This may be as simple as encapsulation, or as complex as an immune reaction, assuming that cell death and tissue necrosis do not occur. 'Reparative' dentine is just such a response: insult the pulp, directly or indirectly, and the process tends to seal it off, to prevent further damage. Such calcification is generally greeted favorably under a foreign lining or filling material, but it also normally occurs anyway with a low-level challenge such as caries. It does not seem to me to be sensible to label a material that provokes such a defensive response, however natural or normal that response may be, as 'bioactive'. Were we to do so we would also be obliged to include formaldehyde, zinc oxide-eugenol, and calcium hydroxide itself under that umbrella, as well as much else, such as a splinter or shrapnel. Note that it does not matter whether the outcome is considered desirable. The mere fact that the stimulus is applied, of whatever kind, and is perceived as a challenge means that the biological defence is automatic. That does not justify labelling the source of the challenge 'bioactive'.

A complication arises with materials or substances that are primarily damaging to tissue, but in that process release from those tissues substances that are indeed bioactive. For example, there are in dentine many biologically important molecules which became bound within it during its development. Should these molecules be released through matrix breakdown they may once again be biologically active and thus be important in reparative or regenerative processes. Such release might occur during mechanical removal, but this is unlikely to be of much importance. Enzymatic or hydrolytic breakdown (if not at too high a $\mathrm{pH}$ ) would perhaps be more important. However, damage by irrigants such as EDTA, dissolving tooth mineral, which would thereby also increase the diffusivity of those substances, and thus release them more quickly or in greater quantity, might be construed as beneficial. It would plainly be wrong to ascribe to that agent, whatever it is, the properties of the released substances and call it bioactive.

There are a number of materials whose physical design is beneficial to tissue growth on or in the structure. Whether or not they have other mechanical functions in the sense of an implant to maintain the relationships of other tissues, whether soft or hard, it is the scale of porosity or texture that is the promoter: they are perhaps describable as topologically conducive to growth. Such scaffolds are clearly effective, but whilst they may provide a surface with compatible or 'recognized' chemistry, it is hard to see how these could be labelled bioactive, with the implication of biochemical modulation. The topological aspect has been stressed for bread [11], yet the effect has been ascribed to 'bioactivity' on the basis of the simulated body fluid test [12]. This makes no sense.

The point is that it is entirely unhelpful to apply the term 'bioactive' indiscriminately in any context where a biological response is elicited. That is, application of the term is fundamentally wrong in the absence of externally-supplied natural biological or quasi-pharmaceutical substances. Sadly, it seems that any action, process or material that provokes a response of any kind whatsoever is automatically labelled 'bioactive' when that response is perceived to be beneficial or desirable in any way. However, on that same basis all substances and materials that are detrimental, because they interfere with the normal physiology, ought also to be termed bioactive, as has already been pointed out. That fact that we do not like the outcome is of no concern in that regard. Even good drugs are bad in excess because they are bioactive.

All that said, there is a conceptual class of material that can truly be described as (beneficially) bioactive, and although there is nothing at present on the market it has been demonstrated in principle [13]. That is, the incorporation of a naturally-occurring biological substance that may stimulate or trigger a natural process that leads to a suitable outcome, such as bone growth or dentine deposition. By definition, it can be a substance or substances normally involved, but their artificial provision enables, facilitates or amplifies 
the pathway. A pharmaceutical with the same effect would also count. Such a condition had been anticipated by Hench:

"Bioactive materials release chemicals in the form of ionic dissolution products, or growth factors such as bone morphogenic protein (BMP), at controlled rates, by diffusion or network breakdown, that activate the cells in contact with the stimuli." [14]

One would expect that the vehicle for such a delivery would be otherwise benign, not representing a challenge in itself, for example, a resorbable, non-inflammatory material (as with the demonstrated gelatine [13]). However, it is clear that the modulating or signalling effects envisaged cannot apply automatically to the "ionic dissolution products" mentioned where these are covered by either the simple chemical or challenge-defence categories already discussed. These kinds of response must be explicitly excluded, by properly controlled experimentation, for the claim to hold. This has not been done. Hench goes on to posit that:

"The key phenomenon [sic] is controlled rates of release of ionic dissolution products, especially critical concentrations of soluble silica [sic] and calcia [sic] ions."

where it is not clear that silicates (which it is presumed were meant, silica not being soluble or ionizable) are other than toxic enough to elicit a challenge defence, or that the calcium (calcia ions do not exist) falls under the 'simple chemical' process heading, especially when he also says

"... rapid release of soluble ionic species and formation of a high surface area hydrated silica and polycrystalline hydroxy carbonate apatite (HCA) bi-layer on the glass surface" [14]

is involved with Bioglass, which statement unwittingly makes both of my points for me. "Rapid release" is not controlled, and "critical concentrations" do not appear to have been demonstrated. The progression from proposition to supposition is worrying.

While the use of BMP is implied in the quotation above as having been demonstrated, no reference is given. Hench then states that

"NovaBone, NovaMin and NovaThera products are all third generation bioactive glass products" [14]

but there is no indication anywhere that BMP is used. In fact, quite the opposite for NovaBone [15]. NovaMin does not appear to have worked as planned [16], while NovaThera is in fact a company name [17] — the product is TheraGlass; neither product has claimed to have BMP.

The question of stimulus has been reviewed by Hoppe et al. [18]. Their Table 1 summarizes what is claimed for a variety of elements, yet most if not all are part of normal physiological processes where it is hard to see that deficiency is likely. A specific stimulatory effect where none would otherwise occur, and in the absence of non-biological chemistry, does not appear to have been demonstrated.

\section{Bone}

In large part, the context of 'bioactivity' research concerns bone growth, and several terms are in common use, supposedly to distinguish processes and conditions, and thereby the usefulness of a material. As has been well said:

"The terms osteoinduction, osteoconduction and osseointegration are frequently,

but not always correctly, used terms in many orthopaedic papers." [19]

The hierarchical sequence used here would appear to be reasonable, but it is not so often followed, which suggests a certain lack. Be that as it may, to take osteo-induction first, the authors expand on that:

"This term means that primitive, undifferentiated and pluripotent cells are somehow stimulated to develop into the bone-forming cell lineage." [19] 
This process seems to presuppose the non-existence of any bone-forming cells at the site, whereas in the contexts relevant now an implant is placed in contact with or very close proximity to bone. It also seems to require that stem cells are everywhere available. It would appear, however, that some kind of appositional growth of that pre-existing bone is then involved, as opposed to the creation of entirely new bone, an entirely distinct proposition: the seeming contradiction is not resolved. Indeed, it is difficult to conceive of any current practical circumstances where completely new, isolated bone needs to be conjured from other tissues, although of clear theoretical interest, taking a long view. Equally clearly, for such growth to occur a trigger is required, a signal to induce that cellular transformation. I shall return to this aspect. However, highly-localized appositional growth could be in itself a useful outcome, assuming, that is, that it is constrained physically or biologically; uncontrolled, it would be pathological.

The next level, 'osteo-conduction' sounds like a process, but in fact general usage would seem to imply that bone tissue growth can occur uninhibited, but also unencouragedthat is, the character allows but does not drive, facilitate or direct (the weak parallel with electrical conduction may be helpful: it permits, passively, but the motive force is external; a property, not a mechanism). But, there is evident confusion, even with specialists:

"Bone conduction, or osteoconduction, is a bone matrix that provides bones with

the materials they need to remain strong." [20]

which is a syntactic and logical mess. They go on to say:

"Osteoconduction provides the guidance, ..."

whereby only a physical presence is necessary, but there is more than an overtone of active direction (but for which there is no evidence of necessity). Elsewhere we find:

"... osteoconduction as an important driving force during bone regeneration ..." [21]

and although it is not clear where the 'drive' might come from, a certain Murphy (in turn citing a Turner) was said to have remarked:

"[The] graft is not osteogenetic, but simply osteoconductive. Provided it be in contact at one or both extremities with other living bone, the graft acts simply as a scaffolding for the growth of the capillaries with their osteogenetic cells as they advance from the living contact extremities into the graft."

which is contradictory. Note that now certain cells are "osteogenetic". Weber [21] then deduces that Murphy

"certainly realized that osteo-conduction was an important driving force for bone regeneration"

again without any indication from where this drive might arise. However, the elaboration has:

“Osteoconduction is defined as a three-dimensional (3D) process of ingrowth ... " [21]

but bad though this is as a definition, the process aspect is explicit (if again contradictory), and seems to be based simply on the ability of the bone to grow (which presumably could apply to the case where there is an absence of scaffold), despite the alternative view:

"Osteo-conduction means that bone grows on a surface." [19] and

"... [the] material acts as a structural framework for bone growth" [22]

This appears to be clear enough, and in accord with Murphy's remark, and at the right level. Overall, the concept seems to be that a surface or scaffold is to be perceived as benign by the growing tissue, in other words completely ignored as of no consequence in itself, only the space matters (cf. the bread scaffold discussed above [11]). Properly inert and uninterfering, such a scaffold is essentially invisible except for the physical contact providing a niche. This is not bioactivity. 
The process of osteogenesis, frequently mentioned in the context, seems to be broadly understood simply as bone growth-'osteoproduction'-and would appear to be a general blanket term that covers in some senses, or arises from, the first two terms. The import implied by the 'genesis' root, however, is one of initiation, from nothing, a role imputed for 'osteoinduction'. It is here that there is supposed to be a signal, but again what this might be is obscure. No clear distinction between terms seems to be made anywhere that helps understand the entirety of such a system. But, as a generality, while 'osteoproduction' is not contentious, 'osteogenesis' is confusing. It becomes more tricky when it is added as a definite stage later on, as seems to be common. The Murphy-Turner quotation above made it the potential outcome of a specific character of a material, which confuses even more.

Now we come to "osseointegration", the key marker, it would seem, of a successful outcome for an implant:

"Osseointegration is the stable anchorage of an implant achieved by direct boneto-implant contact." [19]

Indeed, "rigid fixation" is stressed as the criterion. This can be interpreted in a purely mechanical sense: the interface between the bone and the implant can be no less strong than either material, or at least not appreciably so. It must be a functionally load-bearing union. Quite clearly this could be a pure materials science question: does the newly-formed biological apatite (BAp) adhere chemically to the substrate? Plainly, soft tissue can do no more than wet the surface. The work of adhesion, properly defined, may well be relatively high, but this is not enough: soft tissue is weak, and the van der Waals-mediated interfacial interaction weaker. Further, no matter how robust a fibrous capsule may be, this is never considered a useful outcome. This concept then has no biology involved except that the BAp is deposited in an uncompromised fashion and forms a bond with the underlying oxide on titanium or similar alloys. This is a smooth surface statement.

However, as has been indicated for scaffold materials, surface texture and porosity are important for the better accommodation of the approach and ingrowth of bone (i.e., as a tissue). Now, even if there were to be no actual chemical union of the BAp with the implant, the interpenetration of tissue and substrate provides what is known as mechanical key: this provides resistance to displacement in shear by roughness alone, and in tension when there is a re-entrant topology. No more than that is needed, and the 'strength' of the union begins to approach that of the bone. Were there also to be a bond between the BAp and the oxide the load-carrying capacity in tension would be improved on a simply rough surface, but little extra effect would be expected for the other scenarios. Even then, it is self-evidently improper and unreasonable to ascribe 'bioactivity' to that implant surface. It is a purely passive chemical reaction. This conclusion may perhaps have been cautiously anticipated:

"Ingrowth of bone in a porous-coated prosthesis may or may not represent osseointegration." [19]

It seems obvious from even this small survey, from seemingly authoritative sources (certainly, relied on by many), that all definitions need to be revisited. Plainly, there is more than enough confusion in the literature, with intention and desire prejudicing the interpretation of terms to suit local purposes. Vague, ad hoc, local and inconsistent definitions raise several red flags. It is essential to stand back and take a broad view, then dissect and reconstruct the terminology. To be so widely contradictory is simply extraordinary, and really quite unscientific. Bearing in mind that unless communicated it is not science-i.e., objective systematized knowledge [23], it follows that accuracy and precision are essential. Writing definitions is hard to do well (a fray I hesitate to enter here now), but we may not play Humpty Dumpty [24].

\section{Variations}

Biomineralize, biomimetic, bio-ceramic, biomodification ... such terms are increasingly found, but with similarly weak grounds or nonsensical definitions, as have been 
discussed above. Each could require a similar essay. None of this is helped by statements such as

"Broadly speaking all materials used in dental reconstructions are biomaterials" [5]

where, quite generally, these are prosthetic devices of one kind of another, just as for fillings: alien, with not a cell or physiological process in sight. It is not clear quite what purpose is served by such labels but it is evident that, as with 'biomaterials' (Introduction, [3]) there is a kind of terminological creep to validate or justify: the prefix that overrides logic and science has an apparent cachet. Whether for journals or grant bodies, the bandwagon is joined, juggernaut [25] rolls on. Sadly, this diminishes the advances made in tissue engineering, whereby artificial (i.e., created by artifice) truly biological materials are created, even if through the use of an intermediary foreign body.

'Biomineralization', or commonly_and just as bad-“remineralization", in the dental context refers to the desire to replace hard tissue lost to caries, for example, often with an emphasis on it being 'biomimetic'. Thus:

"Biomimetic remineralization represents a different approach to this problem by attempting to backfill the demineralized dentin collagen with liquid-like amorphous calcium phosphate nanoprecursor particles that are stabilized by biomimetic analogs of noncollagenous proteins." [26]

However, there is no evidence that structure has been recreated, merely that the space has been filled. Whether or not this is beneficial, biomimesis is not demonstrated by such a simple precipitation process, and the implication of remineralization prejudicial. Drop the prefix and the wishful thinking, and plain 'mineralization' would make sense.

We find similarly strong claims in many places, for example:

"The PILP process provided significant recovery of both structure and mechanical properties"

"the volume and structure, including some peritubular dentin, could be recovered after PILP remineralization" [27]

where in fact there is no evidence for a rebuilt structure, as implied, other properties notwithstanding. Indeed, it was also said that there was:

"over growth of mineral at the treated surface and tubule's wall" [27]

which very clearly indicates what is happening: simple precipitation. This state of affairs has been acknowledged:

"morphologies that were distinct from normal dentin with a clear line of demarcation between the outer and sloped portions of the lesion" [28]

and a rational motivation explained:

"Few studies have attempted to define the essential metrics for load bearing integrity of calcified tissues. One such metric is based on a fundamental mechanical property, namely indentation elastic modulus as measured in hydrated tissues, and in this work recovery of this property was determined after applying the PILP process to artificial carious lesions. Thus functional remineralization is the result of a process that yields recovery of physical and chemical properties otherwise lost due to disease." [28]

Plainly, there is no intent here to recreate the dentine structure, just the mechanical and chemical properties-which makes sense in a functional or operational sense, as stated.

There are many papers in this area that make unsubstantiated claims, using misleading terms for pious hopes rather than demonstrated facts, and this spills over into advertising. For example, a toothpaste is said to be

"the first oral care system ... able to regenerate tooth enamel mineral ${ }^{1}$, reversing the early enamel erosion process" [29]

but the footnote says: 
"Acts on early invisible stages of enamel erosion by restoring its mineral content and micro hardness"

which rather gives the game away. The headline claim is patently and admittedly false. In other words, it is only the functional aspect of mechanical integrity that is being obtained: not enamel, or even enamel mineral in the strict sense, just a precipitated coating, albeit apatitic, as the image clearly demonstrates [30,31].

\section{Coda}

From a dispassionate assessment of the nature of the systems involved, the claims made for bioactivity are, at best, overstated, lacking as they do substantive evidence, as competing explanations have not been excluded. At worst, they are wishful thinking. The desirability of such action has apparently taken precedence over actual evidencechemical, physical and biological, and prejudiced interpretation: self-fulfilling prophecies. To recapitulate, the key to understanding is inspection of the actual chemistry, to determine the mechanisms involved. Simple chemical effects that do not involve any biology as such, or an insult that causes a perfectly normal defensive response, cannot sensibly be called 'bioactive' in the directed, positive, therapeutic sense that characterizes most reports. Indeed, it has become apparent that none of these materials can even be described as 'smart': their reactivity is not 'responsive', not reparative. Mechanical outcomes are likewise irrelevant to the definition, albeit a major factor in some cases. When materials are actually available that are the vehicles for any of the many biologically-active substances that offer the possibility of true reparative or regenerative responses, the label will be fully justified and accurate. Until then, it is suggested that much more careful thought is required for its application, as with all such coinings.

Funding: This research received no funding.

Conflicts of Interest: The author declares no conflict of interest.

\section{References}

1. Woodforde, J. The Strange Story of False Teeth; Routledge \& Kegan Paul: London, UK, 1968.

2. Howard, P. Weasel Words; Corgi: London, UK, 1983.

3. Darvell, B.W. Materials Science for Dentistry; Woodhead: Cambridge, UK, 2018.

4. Available online: www.iberdrola.com/innovation/smart-materials-applications-examples (accessed on 25 January 2021).

5. Vallittu, P.; Boccaccini, A.; Hupa, L.; Watts, D. Bioactive dental materials-Do they exist and what does bioactivity mean? Dent. Mater. 2018, 34, 693-694. [CrossRef] [PubMed]

6. Pan, H.B.; Zhao, X.L.; Darvell, B.W.; Lu, W.W. Apatite-formation ability-Predictor of "bioactivity". Acta Biomater. 2010, 6, 4181-4188. [CrossRef] [PubMed]

7. Kokubo, T. Apatite formation on surfaces of ceramics, metals and polymers in body environment. Acta Mater. 1998, 46, 2519-2527. [CrossRef]

8. Hench, L.L.; Splinter, R.J.; Allen, W.C.; Greenlee, T.K. Bonding mechanisms at the interface of ceramic prosthetic materials. J. Biomed. Mater. Res. 1971, 5, 117-141. [CrossRef]

9. ISO 23317. Implants for Surgery —In Vitro Evaluation for Apatite-Forming Ability of Implant Materials; International Standards Organization: Geneva, Switzerland, 2014.

10. Tiskaya, M.; Shahid, S.; Gillam, D.; Hill, R. The use of bioactive glass (BAG) in dental composites: A critical review. Dent. Mater. 2020, in press. [CrossRef] [PubMed]

11. Holmes, J.T.; Jaberansari, Z.; Collins, W.; Leblanc Latour, M.; Modulevsky, D.J.; Pelling, A.E. Homemade bread: Repurposing an ancient technology for low cost in vitro tissue engineering. bioRxiv 2020. [CrossRef]

12. Fiume, E.; Serino, G.; Bignardi, C.; Verné, E.; Baino, F. Bread-derived bioactive porous scaffolds: An innovative and sustainable approach to bone tissue engineering. Molecules 2019, 24, 2954. [CrossRef]

13. Okamoto, M.; Takahashi, Y.; Komichi, S.; Cooper, P.R.; Hayashi, M. Dentinogenic effects of extracted dentin matrix components digested with matrix metalloproteinases. Sci. Rep. 2018, 8, 10690. [CrossRef] [PubMed]

14. Hench, L. The story of Bioglass. J. Mater. Sci. Mater. Med. 2006, 17, 967-978. [CrossRef] [PubMed]

15. Available online: www.meddeviceonline.com/doc/independent-clinical-study-suggests-novabone-0001 (accessed on 25 January 2021).

16. Khijmatgar, S.; Reddy, U.; John, S.; Badavannavar, A.N.; Souzab, T.D. Is there evidence for Novamin application in remineralization? A Systematic review. J. Oral Biol. Craniofac. Res. 2020, 10, 87-92. [PubMed] 
17. Available online: www.biospace.com/article/releases/novathera-ltd-b-bristol-b-and-b-cranfield-universities-b-to-pioneer-newapplications-for-theraglass-based-nanomaterials- / (accessed on 25 January 2021).

18. Hoppe, A.; Güldal, N.S.; Boccaccini, A.R. A review of the biological response to ionic dissolution products from bioactive glasses and glass-ceramics. Biomaterials 2011, 32, 2757-2774. [CrossRef]

19. Albrektsson, T.; Johansson, C. Osteoinduction, osteoconduction and osseointegration. Eur. Spine J. 2001, 10 (Suppl. 2), S96-S101.

20. Available online: www.icoi.org/glossary/bone-conduction-osteoconduction/ (accessed on 25 January 2021).

21. Weber, F.E. Reconsidering osteoconduction in the era of additive manufacturing. Tissue Eng. Part B 2019, 25, 375-386. [CrossRef] [PubMed]

22. Available online: www.orthobullets.com/basic-science/9011/bone-grafting (accessed on 25 January 2021).

23. Darvell, B.W. A Glossary of Terms for Dental Materials Science. 2020. Available online: www.academia.edu/25576805/A_ Glossary_of_Terms_for_Dental_Materials_Science_12th_ed_revised_(accessed on 25 January 2021).

24. Darvell, B.W. Terminological Inexactitudes. Dent. Asia 2006, 2, 54-57.

25. Available online: en.wikipedia.org/wiki/Juggernaut (accessed on 25 January 2021).

26. Niu, L.N.; Zhang, W.; Pashley, D.H.; Breschi, L.; Mao, J.; Chen, J.H.; Tay, F.R. Biomimetic remineralization of dentin. Dent. Mater. 2014, 30, 77-96. [CrossRef] [PubMed]

27. Saeki, K.; Chien, Y.C.; Nonomura, G.; Chin, A.F.; Habelitz, S.; Gower, L.B.; Marshall, S.J. Recovery after PILP remineralization of dentin lesions created with two cariogenic acids. Arch. Oral Biol. 2017, 82, 194-202. [CrossRef] [PubMed]

28. Burwell, A.K.; Thula-Mata, T.; Gower, L.B.; Habeliz, S.; Kurylo, M.; Ho, S.P.; Chien, Y.C.; Cheng, J.; Cheng, N.F.; Gansky, S.A.; et al. Functional femineralization of dentin lesions using polymer-Induced liquid-precursor process. PLoS ONE 2012, 7, e38852. [CrossRef] [PubMed]

29. Regenerate Enamel Science Advanced Toothpaste. Available online: www.regeneratenr5.co.uk/products/advanced-toothpaste (accessed on 23 February 2021).

30. Regenerate Enamel Science Advanced Toothpaste. Available online: cdn.shopify.com/s/files/1/0129/2068/4608/files/enamelchanges-with-advanced-toothpaste_1104x.png?v=1555595838 (accessed on 23 February 2021).

31. Sun, Y.K.; Li, X.K.; Deng, Y.; Suna, J.N.N.; Tao, D.Y.; Chen, H.; Hu, Q.H.; Liu, R.J.; Liu, W.N.; Feng, X.P.; et al. Mode of action studies on the formation of enamel minerals from a novel toothpaste containing calcium silicate and sodium phosphate salts. $J$. Dent. 2014, 42, S30-S38. [CrossRef] 